\title{
PENGANTAR TIPOGRAFI
}

\author{
Dion Eko Valentino \\ Politeknik LP3I Kampus K. Pekanbaru \\ Email: dion.plb@gmail.com
}

\begin{abstract}
Abstrak: Desain grafis merupakan salah suatu cara orang untuk menyampaikan ide agar mudah dimengerti oleh pembaca. Didalam desain grafis terdapat salah satu elemen penting sebagai penunjang dalam memudahkan desainer untuk menyampaikan idenya, yaitu tipografi. Artikel ini menceritakan sejarah dari tipografi, perkembangan serta jenis dan prinsip-prinsip tipografi yang dipakai, agar desain menjadi lebih menarik.
\end{abstract}

Kata Kunci: Tipografi, Desain, Huruf

\section{Pendahuluan}

Era Digital merupakan kata yang tepat untuk menggambarkan keadaan saat ini. Seluruh sektor berlomba-lomba dalam memanfaatkan kemudahan teknologi digital. Mulai dari perusahaan besar hingga perusahaan skala rumahan mencoba mencari peluang dengan beralih kepada media online. Dengan media online tersebut perusahaan dapat melakukan kegiatan operasionalnya dengan menggunakan multimedia. Multimedia adalah penggunaan komputer untuk menyajikan dan menggabungkan teks, suara, gambar, animasi dan video dengan alat bantu (tool) dan koneksi (link) sehingga pengguna dapat bernavigasi, berinteraksi, berkarya dan berkomunikasi (Hofstetter 2001). Sedangkan Menurut McCormick dalam buku M.Suyanto (2005:21) multimedia adalah kombinasi dari paling sedikit dua media input atau output dari data, media ini dapat berupa audio (suara, musik), animasi, video, teks, grafik dan gambar. Jika dilihat dari definisi multimedia menurut para ahli diatas, terdapat salah satu komponen dari multimedia yaitu teks. Alex Sobur mendefinisikan teks sebagai seperangkat tanda yang ditransmisikan dari seorang pengirim kepada seorang penerima melalui medium tertentu atau kode-kode tertentu (2004: 53). Lain halnya dengan penjelasan Eriyanto, Teks hampir sama dengan wacana, bedanya kalau teks hanya bisa disampaikan dalam bentuk tulisan saja, sedangkan wacana bisa disampaikan dalam bentuk lisan maupun tertulis (2001:3). Teks merupakan susunan dari huruf yang digabungkan untuk menjadi kata yang kemudian dari kata tersebut memiliki makna tertentu.

\section{Landasan Teori}

\section{1 Sejarah Huruf dan Cetak Tulisan}

Selama bertahun-tahun, manusia purba berkomunikasi murni dengan suara. Bahasa Lisan memiliki banyak keterbatasan: ia hilang seketika hal tersebut diucapkan dan didengar, dan karena itu bersifat sementara. Cerita, sejarah, dan informasi lainnya tidak dapat disampaikan generasi ke generasi secara permanen, hanya dengan langsung dari mulut ke mulut. Upaya paling awal untuk merekam cerita dan ide adalah melalui gambar gua; yang pertama diketahui bertanggal sekitar 25.000 SM. Gambar-gambar ini, atau piktograf, 
adalah representasi yang sangat sederhana dari orang, tempat, dan benda-benda, dan untuk alasan ini, mereka relatif mudah dipelajari dan dipahami. Meskipun ini adalah bentuk komunikasi tertulis yang sangat sederhana, itu tentu saja lebih permanen daripada suara, dan banyak di antaranya telah selamat dari kerusakan waktu dan masih ada sampai sekarang.

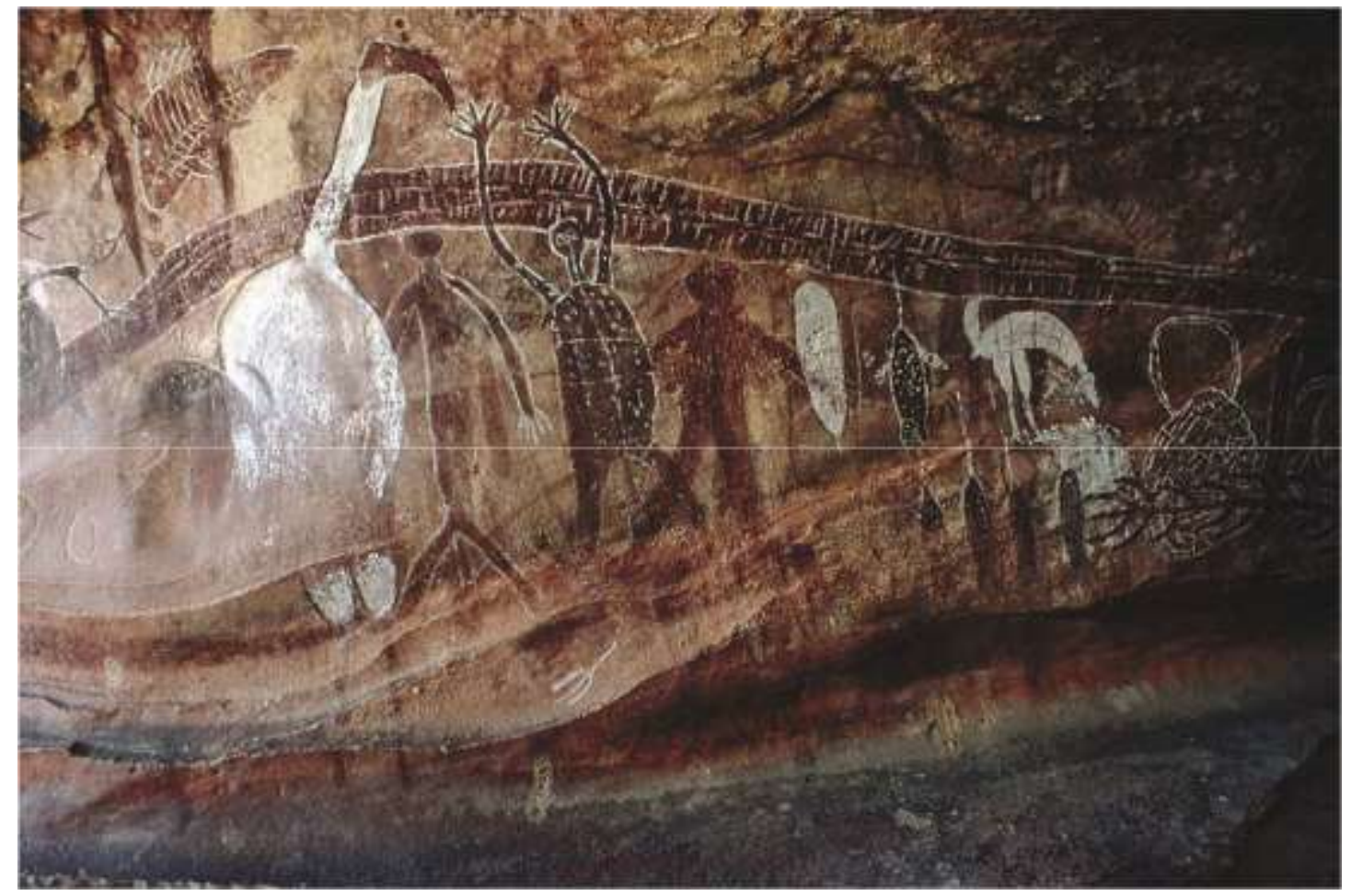

Gambar 1.

Lukisan batu Aborigin ini (sekitar 13.000 SM), terletak di sebuah gua di Queensland, Australia, adalah contoh khas dari yang paling awal bentuk komunikasi tertulis. Foto milik Axel Poignant Archive.

Gambar-gambar yang memiliki makna ini disebut pictograf. Menurut Kamus Merriam Webster, pictograf adalah gambar kuno atau prasejarah atau lukisan di dinding batu, atau salah satu simbol yang dimiliki sistem grafis bergambar. Sekitar 3000 SM orang Sumeria mengembangkan tulisan paku / cuneiform, sebuah sistem penulisan yang terdiri dari bentuk-bentuk berbentuk baji yang diukir di tanah liat dan permukaan keras lainnya. 


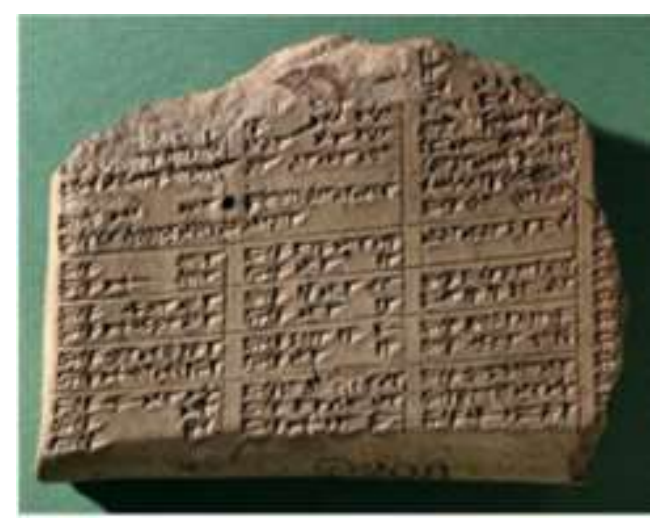

Gambar 2. Cuneiform

Foto milik The British Museum

Pictograf biasanya digunakan sebagai simbol untuk menggambarkan suatu benda. Seperti pada gambar 1 dimana di dinding gua digambarkan simbol berbentuk orang dan binatang. Seiring berlalunya waktu, kebutuhan akan simbol untuk mewakili ide dan konsep lain selain hanya gambar yang merepresentasikan bentuk lebih besar. Hal ini menyebabkan pengembangan ideogram, atau simbol, untuk mewakili ide dan tindakan. Salah satu contoh perubahan dari pictograf ke ideogram adalah pada tulisan hieroglip di mesir kuno. Simbol hieroglif dapat mewakili objek yang mereka gambarkan tetapi biasanya mewakili bunyi atau kelompok bunyi tertentu. Hieroglyph, yang berarti "ukiran suci," adalah terjemahan Yunani dari frase Mesir yang berarti "kata-kata dewa".

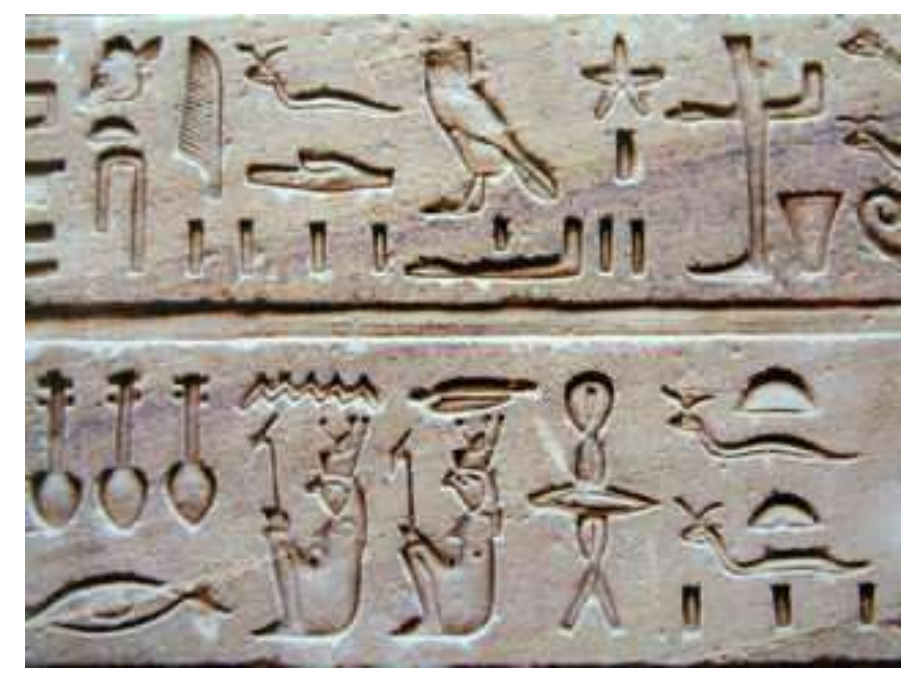

Gambar 3. Hieroglip Mesir

Selain hieroglip mesir juga tulisan kanji dari China, Jepang dan Korea menggunakan ideogram sebagai simbol dalam tulisannya. Hal ini menyebabkan banyaknya jumlah kanji untuk mewakili berbagai macam ideogram. 


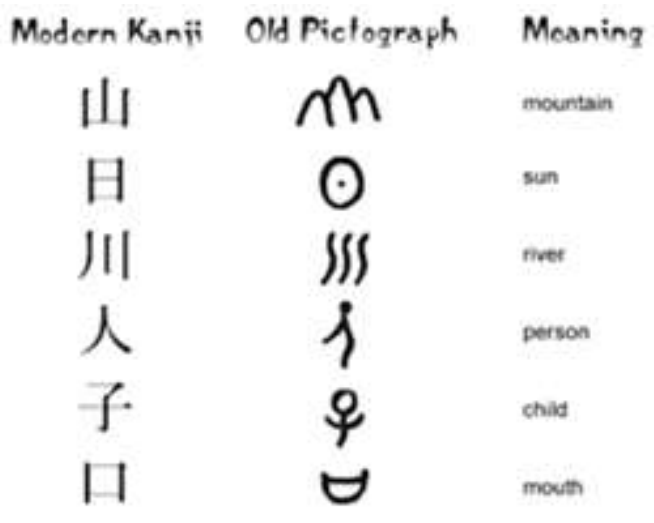

Gambar 4. Ideogram Tulisan Kanji China

Ketika masyarakat menjadi lebih kompleks dimana sistem penulisan yang ada tidak lagi dapat memenuhi kebutuhannya yang semakin meningkat dan tidak lagi memuaskan; mereka membutuhkan sesuatu hal yang dapat mewakili. Kebutuhan ini kemudian mengarah pada pengembangan simbol huruf yang, ketika disatukan, mewakili kata-kata. Orang-orang Fenisia, sebuah masyarakat pedagang dan pengrajin yang terampil di pantai timur Laut Mediterania, mengambil bahasa tulisan selangkah lebih maju dari piktogram dan ideogram orang Sumeria. Sekitar pada tahun 1000 SM orang-orang Fenisia mengembangkan dua puluh dua simbol yang sesuai dengan dua puluh dua suara utama bahasa mereka. Gagasan mereka adalah menghubungkan simbol-simbol ini (mewakili suara) untuk meniru kata-kata yang diucapkan, sehingga menghilangkan kebutuhan untuk menghafal ratusan simbol yang tidak terkait. Ini adalah upaya pertama untuk menghubungkan bahasa tertulis dengan kata yang diucapkan; kita sekarang sering menyebutnya fonetik.

Sekitar tahun 800 SM, orang Yunani melakukan modifikasi pada penemuan kaum Fenisia dan mengambilnya selangkah lebih maju dengan menambahkan vokal dan memberi nama simbol. Mereka juga menggunakan boustrophedon (artinya "seperti bajak sapi"), sebuah sistem di mana seseorang membaca dari kiri ke kanan pada satu baris dan kanan ke kiri pada baris berikutnya.

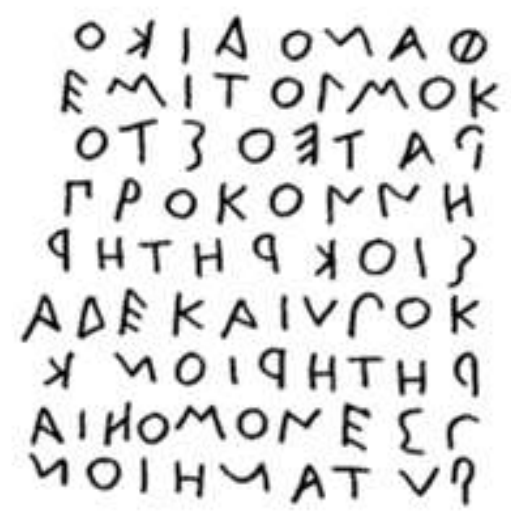

Gambar 5. Sistem penulisan Yunani menggunakan boustrophedon ("bajak sapi”), sebuah sistem di mana seseorang membaca dari kiri ke kanan pada satu baris dan kanan ke kiri pada baris berikutnya. 
Sumber: Type Rules! Strizver,I (2013:5).

Sampai abad kelima belas, semua buku disalin tangan oleh para penulis, sebagaimana dicontohkan oleh banyak manuskrip yang ditulis dengan sangat indah serta memiliki ilustrasi yang dibuat untuk keperluan keagamaan di biara-biara.

Pada tahun 1448, hal tersebut berubah dengan lahirnya percetakan, setelah itu dunia tidak akan pernah sama lagi. Johannes Gutenberg, seorang pandai emas dari Mainz, Jerman, disebutkan sebagai penemu pencetak dengan tipe bergerak, maksudnya adalah cetak pada manuskrip mudah dibawa. Jenis cetak ini juga disebut sebagai pencetakan letterpress, dimana potongan besi yang dipahat menyerupai huruf dicetak kepada kertas sehingga menghasilkan gambar atau tulisan yang baik. Dengan penemuan dari Gutenberg merubah kebiasaan yang ada di dunia. Gutenberg melanjutkan untuk mencetak Alkitab, dimana merupakan buku pertama yang dicetak dari jenis cetak bergerak yang ia temukan. Hal ini menjadi terobosan baru, karena juru tulis tidak perlu lagi menghabiskan waktu berbulanbulan (bahkan terkadang seumur hidup) untuk menyalin buku.

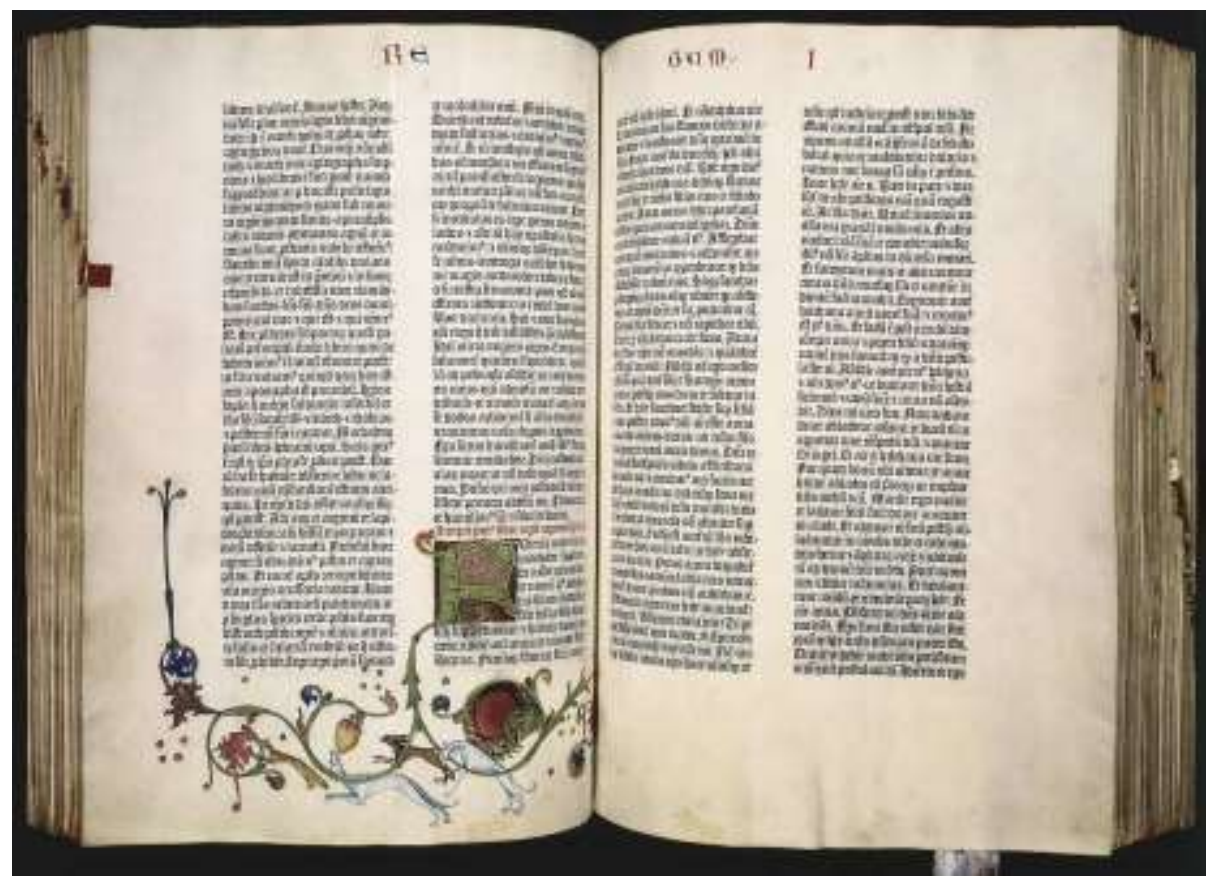

Gambar 6. Alkitab Gutenberg, Mainz, German, 1450-55. Courtesy of Huntington Library.

Perkembangan mesin cetak terus mengalami perkembangan, dimana sampai pada jaman revolusi industri pada abad ke 19. Terosoban mesin cetak mekanik ditemukan akibat dari kurangnya kecepatan dan keandalan hand type metal set composition (pada alat cetak jenis ini, setiap huruf dari setiap kata harus diatur secara manual dengan tangan). Mesin Linotype, ditemukan oleh Ottmar Mergenthaler pada tahun 1880-an, dimana mesin ini mempercepat proses pencetakan (serta memiliki kemampuan untuk membenarkan teks). 


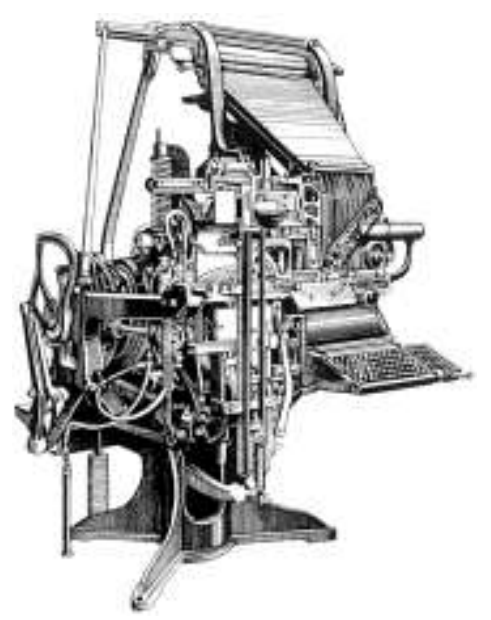

Gambar 7. Mesin Cetak Linotype Ottmar Mergenthaler

Teknologi mengambil lompatan besar di pertengahan 1950-an dengan pengembangan phototypesetting. Beberapa perusahaan, yang paling menonjol adalah perusahaan Mergenthaler dan Intertype, dimana mereka mengembangkan dan meningkatkan proses fotografi tipe pengaturan di mana tipografi dibuat menjadi negative, kemudian cahaya difokuskan pada kertas yang peka terhadap cahaya, menghasilkan gambar dari tipe tersebut. Pengaturan huruf pada saat ini dapat dilakukan secara elektronik, bukan secara mekanis dan manual, dengan pengaturan lebih dari lima ratus karakter per detik. Keunggulan lain mesin elektronik ini yaitu gambar menjadi tajam, koreksi dapat dilakukan secara elektronik.

Salah satu tokoh yang paling menonjol dalam tipografi dan desain tipografi pada 1960an dan 1970-an adalah Herb Lubalin (1918-1981), beliau adalah perancang inovatif yang berasal dari kota New York. Desain dari Lubalin mempengaruhi desain dari para desainer di seluruh dunia. Dia menggunakan tulisan dengan huruf yang rapat, dimana belum pernah dilakukan sebelumnya. Ia pun menggabungkan elemen desain ilustrasi dan tipografi dalam karyanya.

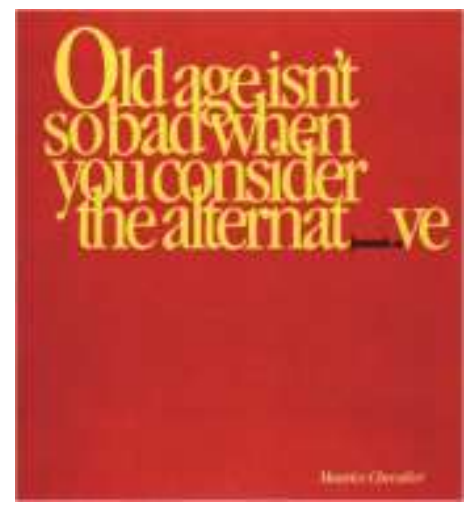

Gambar 8. Salah Satu karya Lubalin

Sumber: Type Rules! Strizver,I (2013:11).

Pada tahun 1985, dunia digemparkan dengan diperkenalkannya komputer Macintosh (Mac), "komputer meja" pertama yang dikembangkan oleh Apple di bawah 
kepemimpinan Steve Jobs. Pabrikan lain, yang dipimpin oleh IBM, sedang mengembangkan versi mereka sendiri, yang kemudian dikenal sebagai komputer pribadi (PC). PC ini memiliki sistem operasi yang berbeda dari Mac tetapi memiliki kemampuan dan fokus yang sama. Pada era ini merupakan masa dimana dimungkinkan bagi siapapun untuk mengatur sendiri tulisan secara pribadi, hal ini dianggap sebagai perintis dalam masuknya era "desktop typography". Teknologi baru yang menarik, dan semakin terjangkau ini semakin berkembang pesat. Pada saat yang sama, aplikasi tata letak halaman, seperti PageMaker dan QuarkXPress, serta program yang lebih berorientasi pada ilustrasi, seperti Adobe Illustrator dan Aldus Freehand, sedang dikembangkan. Ketika memori dan kecepatan komputer desktop meningkat, begitu pula fitur serta kemampuan program-program ini ikut meningkat, dimana termasuk kemampuan untuk mengatur dan menyempurnakan jenis tulisan. Bersamaan dengan itu, perusahaan seperti International Typeface Corporation (ITC), Adobe, Linotype, Compugraphics, dan Berthold mengalihkan fokus mereka untuk mengembangkan versi digital dari perpustakaan jenis huruf yang ada, serta merilis desain baru dan berbeda.

\subsection{Font}

Apakah itu font? Dalam tipografi tradisional, khususnya pada cetak logam (atau cetak panas), font adalah kumpulan karakter logam yang mewakili kumpulan karakter lengkap dari desain tertentu (semua karakter, angka, tanda, simbol, dll.), Semua memiliki berat, gaya, dan ukuran yang sama. Sekarang ini, font mengacu pada kumpulan karakter lengkap dari desain jenis tertentu atau jenis huruf dalam bentuk digital. Meskipun istilah font mengacu pada satu berat dan gaya, font tersebut tidak menentukan ukuran seperti pada zaman cetak logam panas.

Font digital dapat diukur, ukurannya tidak tergantung; semua tipe ukuran dapat diatur dari satu jenis font. Jenis-jenis font digital:

\section{a. Postscript Fonts}

Postscript font dikembangkan oleh perusahaan Adobe pada tahun 1985, Format font jenis ini yang memiliki dua bagian, yaitu screen fonts dan printer fonts. Screen fonts tampilan font yang muncul pada layar media. Printer Fonts merupakan outline yang di cetak oleh tinta printer, kemudian bagian kosong didalam outline yang sudah di print tadi akan diisi oleh semprotan tinta . Proses ini disebut rasterization. Proses pengisian titik- titik tersebut pada computer menggunakan perhitungan khusus yang disebut PostScript, oleh karena itu disebut PostScript Fonts. Contoh dari jenis font postscript font, yaitu: Helvetica, times, times new roman, dll.

\section{b. True Type Fonts}

Format TrueType dikembangkan bersama oleh Apple dan Microsoft pada tahun 1991, beberapa tahun setelah rilis format font PostScript Type 1. Terlepas dari keunggulan teknis format (sebagian besar font sistem pada komputer Mac dan Windows adalah TrueType), format ini tidak pernah menjadi populer di kalangan perancang. Walaupun begitu ada satu keunggulan dari jenis ini yaitu ia hanya memiliki satu file untuk semua ukuran font. Contoh dari jenis font true type yaitu, arial, Tahoma, verdana, dll.

\section{c. Opentype Font}

OpenType merupakan format font yang dikembangkan oleh Adobe dan Microsoft pada akhir 1990-an. Font jenis ini mulai digunakan lebih luas setelah pada tahun 2000, perusahaan Adobe menyertakan dukungan untuk fitur tipografi canggih dalam aplikasi InDesign, PhotoShop, dan Illustrator mereka. Font OpenType mendukung Unicode, yang berarti bahwa 
font OpenType tunggal dapat berisi lebih dari 65.000 karakter. Dengan demikian, satu font dapat digunakan untuk mengatur teks dalam berbagai bahasa, seperti Inggris, Ceko, Rusia, Yunani atau Esperanto. Font OpenType adalah cross-platform (File yang sama dapat digunakan pada komputer Mac ataupun Windows).

Beberapa tokoh terkenal dalam bidang desain font yaitu:

a. Morris Fuller Benton (1872-1948) adalah seorang desainer jenis huruf dari Amerika yang sangat berpengaruh, Benton mengepalai departemen desain American Type Founders (ATF) dari tahun 1900 hingga 1937. Selama kurun waktu tersebut ia bertanggung jawab untuk memperkenalkan banyak sekali desain huruf ke dalam penggunaan umum. Ia berhasil menghidupkan kembali beberapa desain huruf yang penting seperti, TF Bodoni, Souvenir, Goudy Old Style, Cheltenham. Benton juga membuat desain jenis huruf baru yaitu, Hobo, Bank Gothic, Broadway, Franklin Gothic, Alternate Gothic, News Gothic, dan Agency Gothic. Jumlah totalnya kurang lebih ia berhasil mengembangkan 200 jenis desain huruf.

b. Oswald Bruce Cooper (1879-1940) merupakan seorang seniman huruf, perancang grafis, dan pendidik dari Amerika. Awal mula Cooper masuk ke bidang tipografi adalah ketika ia belajar menulis surat dengan Frederick Goudy di Sekolah Ilustrasi Frank Holme. Dia melakukannya dengan sangat baik dalam menulis, kemudian dia menjadi guru dan direktur di sekolah, di bawah bimbingan dan bimbingan Goudy. Pada tahun 1904 Cooper (yang juga dikenal sebagai Oz Cooper) dan Fred Bertsch, salah seorang muridnya, membentuk studio yang bernama Bertsch \& Cooper. Studio ini menjadi terkenal karena hasil dari tulisan tangan mereka dan akhirnya tumbuh menjadi studio penataan huruf dan desain layanan lengkap dengan lebih dari lima puluh karyawan. Cooper kemudian mendesain tipografi lengkap, banyak yang didasarkan pada beberapa tulisan tangan yang dia lakukan untuk klien. Beberapa karya milik Cooper yaitu, Oz Poster, Maiandra, ITC Ozwald, ITC Highlander, serta Cooper Black yang sangat populer.

c. Stanley Morison (1889-1967) adalah seorang juru ketik, sejarawan, dan perancang terkenal Inggris. Pada 1922 Morison mendirikan Lembaga Fleuron, yang didedikasikan untuk tipografi. Dia kemudian menjadi konsultan tipografi untuk Cambridge University, Times (surat kabar harian London), dan Monotype Corporation, di mana dia berperan dalam mengidupkan kembali jenis huruf bersejarah seperti Baskerville dan Bembo. Morison mungkin terkenal karena mengembangkan (bersama dengan Victor Lardent) jenis huruf Times New Roman yang sangat mudah dibaca untuk surat kabar harian Times, yang menugaskannya untuk merancang pengganti Times Old Roman setelah ia mengkritik buruknya kualitas pencetakan kertas selama masa jabatannya sebagai konsultan tipografi mereka. Karya Morison yang sangat terkenal adalah jenis huruf Times New Roman.

d. Hoefler \& Frere-Jones adalah perusahaan desain yang berbasis di New York (awalnya The Hoefler Type Foundry, didirikan 1989) dijalankan oleh presiden dan pendiri Jonathan Hoefler (1970-) dan kepala sekolah dan direktur tipografi Tobias Frere-Jones (1970-). Mereka menggabungkan silsilah tipografi mereka yang mengesankan untuk merancang beberapa tipografi paling terkenal, termasuk Gotham, Archer, Sentinel, Knockout, Titling, Whitney, Vitesse, Sans Ideal, Requiem, dan Tungsten. Karya mereka dikenal sebagai karya dengan kinerja tinggi, gaya tinggi, serta fitur yang kuat, baik teknis maupun estetika. Selain koleksi font yang tersedia secara komersial, mereka telah berkolaborasi dalam proyek tipografi untuk Wall Street Journal, Martha Stewart Living, Nike, Pentagram, GQ, Esquire, New York Times, Business 2.0, dan New York Times Magazine. Karya Hoefler termasuk dalam koleksi permanen Cooper-Hewitt National Design Museum (bagian dari Smithsonian Institution) di New York. Pada tahun 2002, Asosiasi Typographique Internationale (ATypI) memberikan Hoefler penghargaan paling bergengsi, yaitu penghargaan Prix Charles Peignot atas kontribusi luar biasa untuk desain. Dia mungkin paling dikenal karena Hoefler Text, yang dirancang untuk Apple Computer dan termasuk dalam sistem operasi Macintosh. Karya Frere-Jones termasuk dalam koleksi permanen Victoria and Albert Museum di London. Pada tahun 2006 ia menjadi orang Amerika pertama yang menerima Hadiah Gerrit Noordzij, yang 
dipersembahkan oleh Akademi Kerajaan Den Haag untuk menghormati kontribusi uniknya dalam desain huruf, tipografi, dan jenis pendidikan. Frere-Jones beserta desainer Matthew Carter mengajarkan desain jenis huruf dalam program YFA School of Art MFA.

\section{3 Typography}

Dalam bukunya yang berjudul "An Approach to Print: A Basic Guide to the Printing Processes" (1971) Roy Brewer menjelaskan bahwa typography dapat memiliki pengertian luas yang meliputi penataan dan pola halaman, atau cetakan atau dalam arti yang lebih sempit hanya mencakup pemilihan, pengaturan, dan berbagai hal yang berkaitan dengan pengaturan baris-baris huruf (typeset), tidak termasuk ilustrasi dan elemen lainnya pada halaman yang dicetak “. Dalam buku "Tipografi Dalam Desain Grafis", Danton Sihombing mengemukakan bahwa pengetahuan mengenai huruf dapat dipelajari dalam sebuah disiplin seni yang disebut tipografi (typografi). (Sihombing, 2001:3). Danton Sihombing mengemukakan bahwa Tipografi merupakan representasi visual dari sebuah bentuk komunikasi verbal dan merupakan properti visual yang pokok dan efektif (Sihombing, 2001: 58).

Tipografi adalah salah satu bahasa dalam desain grafis yang tidak berdiri sendiri secara ekslusif, ia sangat erat terkait dengan bidang keilmuan lain seperti komunikasi, teknologi, psikologi dan lainnya (Rustan, 2011:2).

Dalam bukunya yang berjudul "Stop, Think, Go, Do: How Typography and Graphic Design Influence Behavior", Steven Heller menuliskan bahwa terdapat 8 prinsip tipografi dan desain yaitu, Inform, Advocate, Play, Caution, Entertain, Express, Educate, and Transform.

a. Inform adalah bagaiamana kita menginformasikan suatu hal kepada pembaca atau audien dengan mengangkat suatu topik masalah, esensi dari suatu hal, atau memberikan pemikiran terhadap sesuatu yang menyebabkan kekhawatiran.

b. Advocate merupakan prinsip yang paling umum dilakukan oleh desainer, dalam hal ini desainer biasanya dipekerjakan dalam pembuatan pesan dimana pesan tersebut harus dapat menggugah keinginan audien untuk bisa mendukung, ikut terlibat, dalam suatu acara atau kegiatan.

c. Play pada prinsip ini biasanya digunakan oleh desainer untuk menghibur, mengekspresikan, serta memberi informasi kepada audien.

d. Caution prinsip ini merupakan prinsip yang paling klasik dalam penyampaian pesan dalam desain grafis. Contoh pesan yang menggunakan prinsip ini yaitu, Jangan Masuk, Dilarang Melintas, Awas Anjing Galak, dll. Prinsip ini digunakan dengan tujuan sebagai peringatan bagi audien.

e. Entertain merupakan salah satu prinsip yang paling disukai oleh semua orang. Tidak ada orang yang merasa terancam oleh hiburan, walaupun memiliki berbagai macam jenis hasil tetapi prinsip ini memiliki satu tujuan mendasar yaitu untuk membawa kesenangan bagi penikmatnya.

f. Express, merupakan prinsip yang sering digunakan saat ini dan mengalami pertumbuhan yang pesat, karena lebih banyak desainer menggunakan kata-kata dan slogan yang dirancang secara grafis sebagai sarana untuk mengekspresikan kepercayaan, filosofi, dan sebagai cerminan pribadi dengan tujuan mempengaruhi orang lain. 
g. Educate, bisa disebut sebagai kombinasi dari seluruh prinsip yang telah dijelaskan diatas. Secara khusus memiliki fungsi sebagai pemberi pesan pengetahuan yang rinci kepada audien.

h. Transform, menggunakan permainan kata - kata visual dan manipulasi grafis untuk bisa masuk kepada sudut pandang audien.

Jason Tselentis juga menjabarkan beberapa prinsip dalam bukunya yang berjudul "Typography Referenced" (2012;211) yaitu:

\section{a. Format}

Sebagai desainer pertama-tama yang harus diperhatikan adalah ukuran dan proporsi halaman atau layar tempat bekerja. Meskipun setiap format memiliki batas tepi yang mengandung elemen desain, hal tersebut tidak boleh membatasi kreatifitas desainer.

\section{b. Typography Selection}

Salah satu metode terbaik untuk menentukan jenis huruf yang akan digunakan adalah memiliki pemahaman yang jelas tentang penerapannya. Apakah jenisnya digital atau cetak? Apakah ini membutuhkan serangkaian bobot dan postur? Jika memerlukan beragam simbol dan angka, apakah jenis huruf memiliki set lengkap opsi OpenType untuk angka? Sementara setiap jenis huruf memiliki tampilan dan nuansa yang berbeda, penerapannya pada akhirnya menentukan kegunaannya.

\section{c. Reading Direction and Scanning}

Budaya Barat membaca bahasa tertulis dari kiri ke kanan, yang biasanya menempatkan pandangan pertama pembaca di sudut kiri atas format. Dari sana, pembaca memindai dari kiri ke kanan, secara diagonal ke baris berikutnya, dan kembali lagi dari kiri ke kanan. Pola pemindaian berbentuk $\mathrm{Z}$ ini sering terjadi ketika membaca jenis teks (212) di majalah atau buku, serta dengan media digital seperti konten yang ditemukan di Internet.

\section{d. Grid}

Grid adalah alat yang memungkinkan seorang desainer untuk membuat komposisi.

\section{e. Hierarchy}

Hierarki dalam tipografi mengacu pada tingkat kepentingan yang ingin diungkapkan atau disampaikan oleh tulisan pada media yang digunakan, kemudian juga apakah berbasis cetak atau di layar. Berbagai faktor dapat mengindikasikan hierarki seperti, ukuran bentuk huruf, bobot bentuk huruf, karakteristik desain bentuk huruf, warna teks, kontras teks dengan latar belakang, posisi dan orientasi teks pada halaman atau layar. Faktor-faktor ini saling berhubungan satu sama lain dan juga dalam kaitannya dengan gambar, ruang margin, dan ruang antara garis-garis pada halaman. Untuk teks layar berbasis gerak, karakteristik animasi, harus terlihat berapa lama elemen terlihat, bagaimana elemen bergerak ke dalam, di luar, dan di sekitar layar dan juga bagaimana pergerakan tersebut memengaruhi hierarki.

\section{f. Symmetry and Asymmetry}

Desainer grafis dapat mencapai komposisi seimbang melalui komposisi simetris atau asimetris. Tata letak simetris dihasilkan ketika sisi kiri dan kanan komposisi menerima bobot yang sama. Tata letak cermin yang dicitrakan ini seringkali menghasilkan kerja yang kurang dinamis daripada opsi kontras asimetri. Komposisi asimetris terjadi ketika tidak ada yang sama antara kiri dan kanan. Ini cenderung kurang statis daripada kerja simetris dan tidak bergantung pada pusat, di mana semuanya jatuh ke tempat yang nyaman. 


\section{g. White Space}

Desainer biasanya menyebut area komposisi yang tidak termasuk teks, gambar, atau elemen grafis dengan sebutan ruang putih atau ruang negatif. Beberapa desainer merasa bahwa dengan menggunakan ruang putih pada desainnya dapat memberikan efek yang bagus pada tata letak, berbeda jika hanya dengan tata letak dimana desainer terlalu banyak memakai elemen grafis. Secara formal, ruang putih memungkinkan pembaca memiliki kesempatan untuk fokus pada elemen atau elemen yang paling menuntut perhatian dari pembaca itu sendiri. Secara konseptual, ruang putih dapat melanjutkan pesan mendasar yang diharapkan oleh perancang untuk disampaikan kepada pemirsa. Desainer harus menggunakan ruang putih secara hemat dan fungsional, karena jika terlalu banyak menggunakan ruang putih dapat membuat komposisi terlihat steril atau kosong.

\section{h. Contrast}

Kontras adalah salah satu cara terbaik untuk membuat diferensiasi antara elemen grafis. Dengan tipografi, kontras dalam ukuran, berat, lebar, warna, posisi, dan jenis huruf hanyalah beberapa cara untuk memisahkan informasi atau menarik perhatian pembaca. Dengan kontras tipografi, pembaca segera melihat apa yang paling penting alih-alih dipaksa untuk membaca dan membuat penilaian sendiri.

\section{i. Typeface Pairing}

Memasangkan beberapa jenis huruf harus lebih tentang kontras daripada kesamaan jenis. Misalnya, menggunakan jenis huruf Helvetica dan Arial bersama-sama dalam komposisi, tidak akan banyak gunanya, rata-rata pembaca tidak akan melihat perbedaan antara bentuk huruf. Jadi, bagaimana tepatnya desainer memutuskan jenis huruf mana yang bekerja dengan baik jika dipasangkan bersama? Sayangnya, tidak ada resep, tidak ada perangkat lunak yang dapat memutuskan, serta klien juga jarang menawarkan saran kreatif. Salah satu cara yang paling membantu adalah mengetahui sebanyak mungkin jenis huruf. Tidak ada masalah dengan pemasangan, tetapi pastikan font yang dipilih menghormati konten, memastikan keterbacaan pembaca.

Tipografi merupakan hal yang sering ditemui oleh manusia. Dalam hal yang berhubungan dengan desain biasanya akan ditemukan unsur tipografi. Hal ini merujuk pada peran tipografi itu sendiri dimana sabagai pengantar komunikasi dari ide kepada audien atau pembaca. Unsur-unsur tipografi dapat kita temukan dalam koran, majalah, poster, brosur, $\mathrm{dsb}$. Tipografi tidak dapat dispisahkan dalam membuat desain yang dapat memudahkan pembaca dalam membaca maksud serta ide yang ingin disampaikan.

Desain huruf mirip dengan jenis desain produk lain karena menggabungkan ekspresi pribadi dan interpretasi sesuai dengan kebutuhan dan tren zaman. Seiring perubahan teknologi, masyarakat juga secara keseluruhan ikut berubah, hal ini dapat dilihat dari selera dan gaya pribadi yang berubah, salah satu contohnya keinginan untuk tampil lebih menonjol di tengah keramaian. Mobil, furnitur, arloji, pakaian, dan bahkan barang-barang rumah tangga, seperti telepon, pemanggang roti, dan cangkir the. Semuanya merupakan barang fungsional penting yang terus berubah dan dirancang ulang, dan kemudian dibeli kembali oleh konsumen. Sama halnya dengan tipografi, pilihan jenis huruf yang tepat sangat penting untuk keberhasilan dan keefektifan pesan anda.

Beberapa tipografi, dipilih karena fungsinya, sementara yang lain dipilih karena dampaknya, kepribadiannya, dan untuk membuat pernyataan, seperti kebanyakan 
tampilan pada desain. Pada pandangan pertama banyak tipografi akan terlihat mirip dengan mata yang tidak terampil, tetapi seiring dengan waktu, anda akan dapat tidak hanya melihat perbedaannya tetapi juga memahami bagaimana perbedaan itu penting untuk efektivitas dan daya tarik pekerjaan anda.

Sama dengan tubuh manusia, huruf memiliki berbagai organ yang berbeda. Penggabungan seluruh komponen dari suatu huruf dapat menjadi identifikasi visual yang dapat digunakan untuk membedakan huruf yang satu dengan huruf yang lain. Berikut ini merupakan bagian organ pada huruf yang diterangkan oleh Ilene Strizver (2013:39).

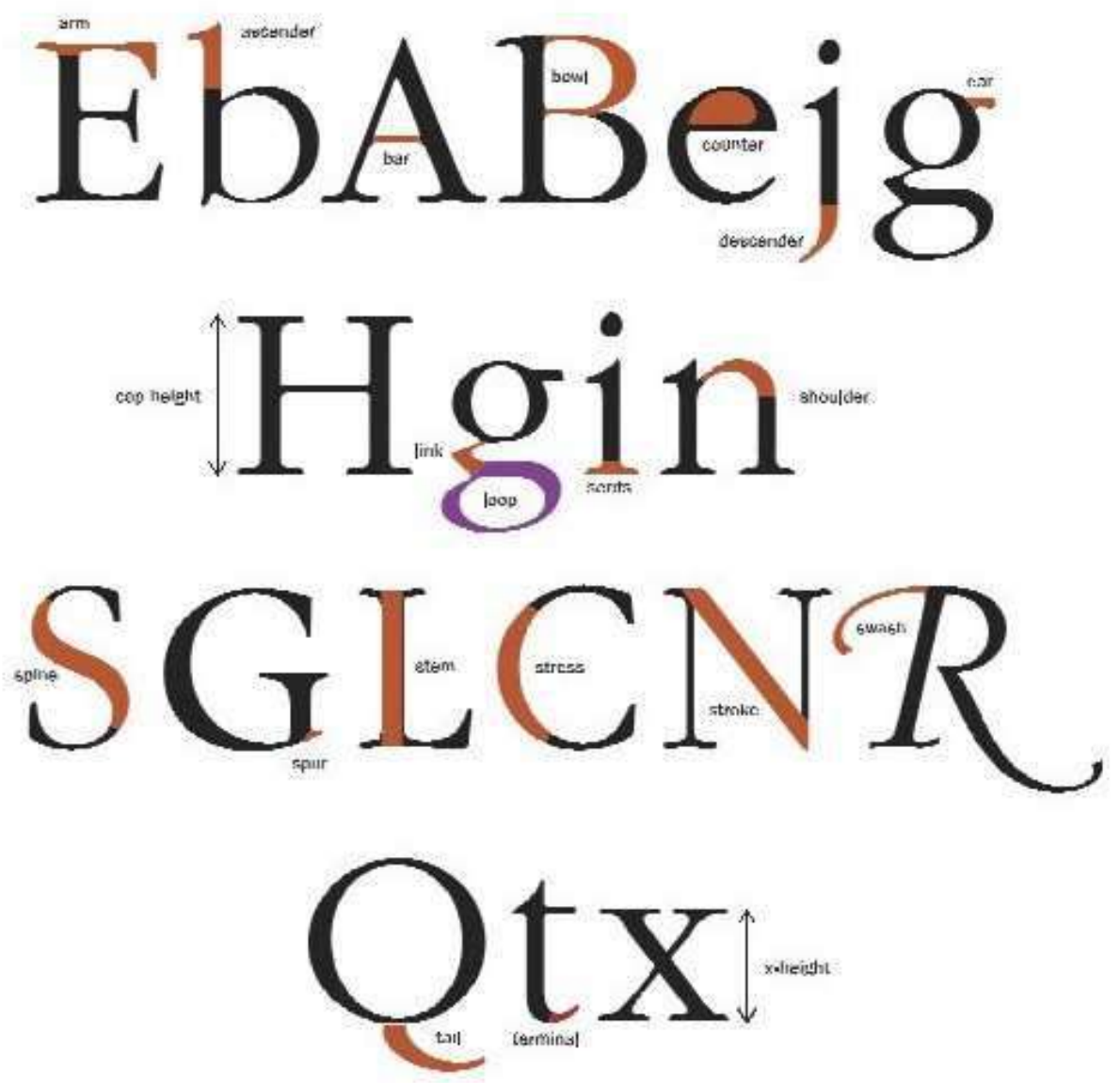

Gambar 8. Organ Huruf

(Strizver, I. 2013;39)

a. Arm: garis horizontal atau diagonal atas yang terpasang di satu ujung dan bebas di ujung lainnya.

b. Ascender: Bagian dari karakter huruf kecil (b, d, f, h, k, l, t) yang memanjang di atas ketinggian huruf kecil $\mathrm{x}$.

c. Bar: garis horisontal dalam karakter seperti A, H, R, e, atau f.

d. Bowl: Stroke melengkung yang menciptakan ruang tertutup dalam karakter (yang kemudian disebut counter).

e. Cap Height: Tinggi huruf kapital dari garis dasar ke atas topi, biasanya ada pada karakter (E, H, I, dll).

f. Counter: Ruang sebagian atau seluruhnya tertutup dalam karakter.

g. Descender: Bagian dari karakter (g, j, p, q, y, J) yang menurun di bawah garis dasar. 
h. Ear: garis kecil yang terdapat diatas atas huruf g.

i. Link: garis yang menghubungkan bagian atas dan bawah pada huruf g.

j. Loop: Bagian bawah dari huruf kecil g.

k. Shoulder: Garis lengkung pada huruf h, m, atau n.

1. Spine: Lekukan melengkung utama pada huruf S.

m. Spur: garis kecil yang mencuat, biasanya ditemukan pada huruf kapital G.

n. Stem: garis vertikal lurus atau garis diagonal lurus.

o. Stress: Arah penebalan pada garis melengkung.

p. Stroke: Garis lurus atau melengkung.

q. Swash: Sebuah hiasan dekoratif menggantikan terminal atau serif.

r. Tail: Garis kecil pada turunan huruf Q atau garis diagonal pendek dari huruf R.

s. Terminal (or Finial): Akhir dari stroke tidak diakhiri dengan serif.

t. $\quad$-Height: Tinggi huruf kecil biasanya didasarkan pada huruf kecil x, tidak termasuk ascenders dan descenders.

Ilene Strizver $(2013 ; 40)$ mengkategorikan beberapa jenis huruf kedalam beberapa kategori, yaitu:

a. Serif

Kategori ini bisa disebut sebagai kategori terbesar pada tipografi dengan penyebut yang sama: semua memiliki serif. Serif dapat dideskripsikan sebagai ekstensi, tonjolan, atau, lebih tepatnya, sapuan akhir yang memanjang dari ujung karakter. Meskipun sifatnya dekoratif dan bergaya, mereka dikatakan meningkatkan keterbacaan dengan mengarahkan mata dari satu karakter ke karakter berikutnya. Mereka juga berfungsi untuk membedakan tipografi yang mirip satu sama lain. Dibawah ini merupakan beberapa jenis tulisan yang masuk kedalam kategori serif

1) Oldstyle

Kategori tipografi yang berasal dari akhir abad kelima belas dan pertengahan delapan belas ini memiliki ciri dengan goresan melengkung dengan sumbu condong ke kiri, sedikit kontras antara goresan tebal dan tipis, serif kepala (biasanya miring), dan serif braket.

Contoh: Adobe Caslon Pro

\title{
abcdefghijklmnopqrstuvwxyz ABCDEFGHIJKLMNOPQRSTU
}

Gambar 9. Adobe Caslon Pro

(Strizver, I, 2013:40)

\section{2) Transitional}

Tipografi dalam kategori ini mewakili abad kedelapan belas pada masa transisi antara gaya lama dan desain modern. Mereka memiliki karakteristik sebagai berikut: sumbu stroke melengkung hampir tidak condong atau lebih vertikal daripada diagonal; ada lebih banyak kontras antara sapuan tebal dan tipis daripada di gaya lama; dan serif lebih tipis, pipih, dan dikurung.

\section{abcdefghijklmnopqrstuvwxyz ABCDEFGHIJKLMNOPQRSTU}

\author{
Gambar 10. ITC New Baskerville
}

(Strizver, I, 2013:41) 


\section{3) Modern}

Gaya halus dan lebih halus ini dicirikan oleh kontras tinggi atau dramatis antara goresan tebal dan tipis, goresan melengkung pada sumbu vertikal, dan serif horizontal dengan sedikit atau tanpa bracketing.

\section{abcdefghijklmnopqrstuvwxyz ABCDEFGHIJKLMNOPQRSTUV}

Gambar 11. ITC Bodoni Twelve

(Strizver, I, 2013:41)

\section{4) Clarendon}

Gaya ini dipopulerkan di tahun 1850-an memiliki tekanan berat vertikal yang kuat; serif berat, dikurung (biasanya persegi); dan sedikit kontras stroke.

\section{abcdefghijklmnopqrstuvwxy ABCDEFGHIJKLMNOPQRST}

Gambar 12. Clarendon

(Strizver, I, 2013:41)

\section{5) Slab or Square Serif}

Sebagai gaya awal abad ke-19, tipografi ini memiliki serif persegi yang sangat berat, sedikit atau tidak ada tanda kurung, dan hampir tidak ada perbedaan stroke, tampak seperti monostroke, yaitu, semua guratan memiliki lebar yang sama. Mereka sering berbentuk geometris atau persegi.

\section{abcdefghijklmnopqrstuvwxyz ABCDEFGHIJKLMNOPQRSTUV \\ Gambar 13. ITC Lubalin Graph}

(Strizver, I, 2013:41)

6) Glyphic

Tipe ini memiliki sumbu vertikal, kontras goresan minimum, dan sering memiliki serif segitiga atau flaring.

\section{ABCDEFGHIJKLMNOPQRSTUVWXYZ ABCDEFGHIJKLMNOPQRSTUVW}

Gambar 14. Cooperplate Gothic

b. Sans Serif

(Strizver, I, 2013:42) 
Sans berasal dari Bahasa Perancis, yang berarti "tanpa," tipografi ini tidak menggunakan serif (sans serif). Gaya ini memiliki popularitas yang tinggi karena kesederhanaan mereka, serta penampilan mereka yang agak industrial. Berikut ini adalah beberapa kategori tipografi sans serif yang paling umum.

\section{1) 19th-Century Grotesque}

Gaya ini merupakan sans serif populer yang pertama. Fitur-fiturnya yang membedakan adalah kontras dalam berat stroke, terdapat mangkuk ganda (juga disebut sebagai dua lantai).

\section{abcdefghijkImnopqrstuvwxyz ABCDEFGHIJKLMNOPQRSTUVWXYZ}

Gambar 15. Franklin Gothic

(Strizver, I, 2013:42)

\section{2) Geometric}

Jenis huruf ini memiliki bentuk geometris yang kuat, seperti lingkaran sempurna, dll.

\section{abcdefghijkImnopqrstuvwxyz ABCDEFGHIJKLMNOPQRSTUVW}

Gambar 16. ITC Avant Garde Gothic

(Strizver, I, 2013:43)

\section{c. Scripts}

Desain ini mewakili kategori besar tipografi yang berasal dari atau meniru tulisan tangan atau kaligrafi. Goresan jauh lebih mengalir daripada tipografi tradisional.

1) Formal

Tulisan yang sangat elegan ini dikarakteristikkan dengan putaran yang mengalir dan timbul dengan sapuan ritmis serta berirama. Desain ini paling sering dihubungkan dengan bentuk tulisan lama dan meniru tulisan tangan penulis kaligrafi abad ke-19.

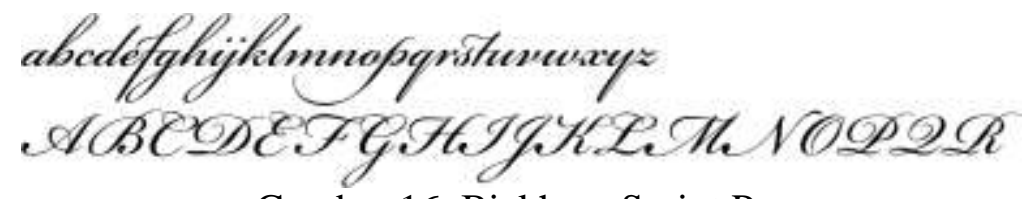

Gambar 16. Bickham Script Pro

(Strizver, I, 2013:43)

\section{2) Casual And Brush Script}

Jenis tulisan ini dirancang agar terlihat informal, seolah-olah dengan cepat digambar dengan pena, kuas, atau alat tulis serupa. Sapuan mereka dapat dihubungkan atau tidak, dan mereka cenderung terlihat ramah, dan santai.

\section{abedelfhijklmnopqusturweys ABCDEFGHIJKLMNOPQRSTUVWXYZ}

Gambar 17. Mistral

(Strizver, I, 2013:44) 


\section{d. Calligraphic}

Gaya pada kategori ini berusaha meniru tulisan atau tulisan kaligrafi yang karyanya digambar tangan dan dibuat khusus untuk setiap pekerjaan.

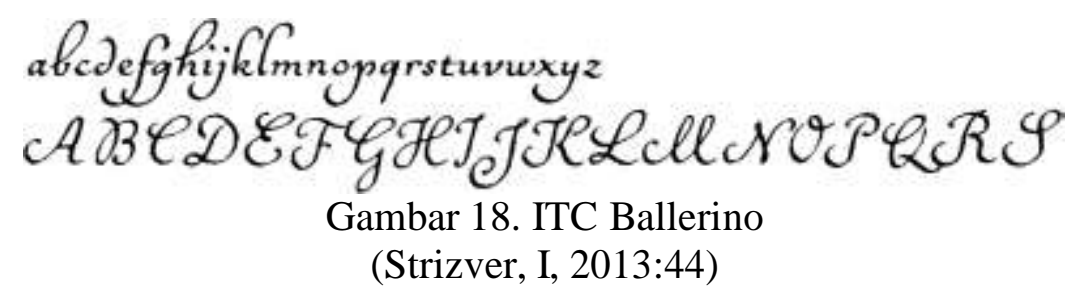

\section{e. Handwriting}

Tipografi tulisan tangan adalah interpretasi tipografi dari tulisan tangan atau pencetakan gaya tulisan tangan yang sebenarnya. Gaya ini merepresentasikan gerkan tangan yang unik, goyang, dan tidak beraturan, seperti pada aslinya seseorang yang sedang menulis.

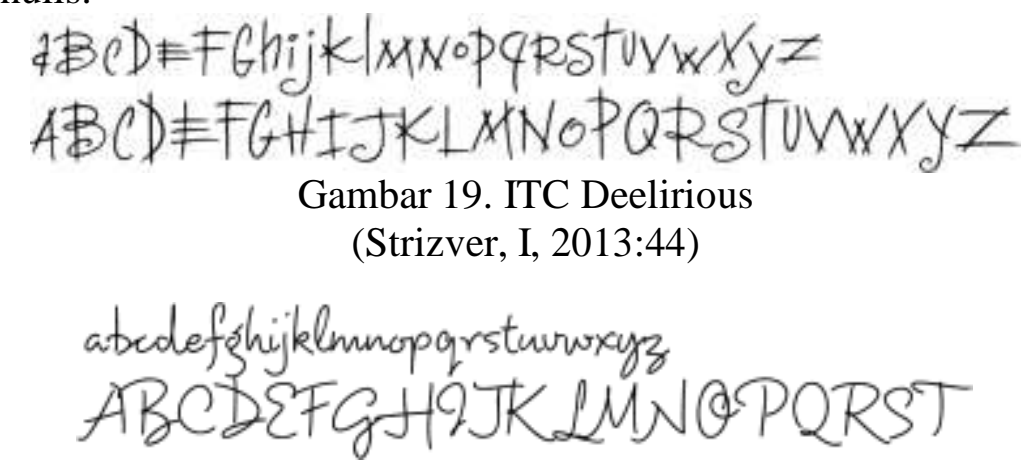

Gambar 20. ITC Dartangnon

(Strizver, I, 2013:4)

\section{f. Blackletter}

Jenis kategori huruf Blackletter ditandai oleh tekstur yang padat, hitam, dan bagian huruf dihias. Huruf kecil terdiri dari bentuk-bentuk sempit dan bersudut dengan goresan dan serif yang tebal dan dramatis.

\section{abcicighijklntuopqrstuvmaxy

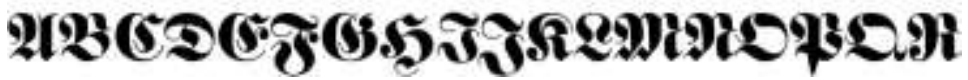

Gambar 21. Fette Fraktur

(Strizver, I, 2013:45)

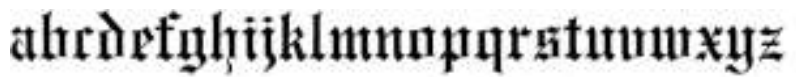

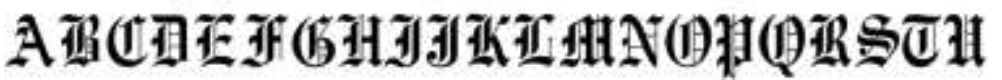

Gambar 22. Engravers Old English

(Strizver, I, 2013:45)

\section{g. Tilting Fonts}

Desain jenis ini telah dirancang khusus untuk pengaturan judul atau tampilan. Font 
titling berbeda dari jenis lain karena skala, proporsi, dan detail desainnya telah diubah agar terlihat terbaik pada ukuran yang lebih besar. Ini biasanya termasuk kontras berat dan proporsi yang sering lebih tebal.

\title{
ABCDEFGHIJKLMNOPQRSTU
}

Gambar 23. ITC Golden Cockerel Titling

(Strizver, I, 2013:45)

\section{ABCDEFGHIJKLMNOPQR ABCDEFGHIJKLMNOPQRST}

Gambar 24. Bembo and Bembo Titling (Strizver, I, 2013:45)

h. Opticals and Size-Sensitive Fonts

Dalam kategori ini jenis tulisan dibuat berbagai macam ukuran sehingga agar jenis tulisan ini bisa menyesuaikan dengan ukuran cetak.

\author{
abcdefghijklmnopqrstuvwxyz \\ ABCDEFGHIJKLMNOPQRSTUV \\ abcdefghijklmnopqrstuvwxyz \\ ABCDEFGHIJKLMNOPQRSTUV \\ abcdefghijklmnopqrstuvwxyz \\ ABCDEFGHIJKLMNOPQRSTUVW \\ abcdefghijklmnopqrstuvwxyz \\ ABCDEFGHIJKLMNOPQRSTUVW
}

Gambar 25. Warnock Pro Opticals: Caption, Regular, Subhead, and Display

(Strizver, I, 2013:46) 


\section{Daftar Pustaka}

[1] Armstrong, Gary M.dan Kotler, P. 2009. Marketing: An Introduction. Pearson Prentice Hall.

[2] Brewer, Roy. 1971. An Approach to Print: A Basic Guide to the Printing Processes, illustrated edition. London: Blandford Press. Curtin, Jeremiah.

[3] Eriyanto. 2001. Analisis Wacana: Pengantar Analisis Teks Media. Yogyakarta:LKiS.

[4] Heller, Steven and Ilic, Mirko. 2012. Stop, Think, Go, Do: How Typography and Graphic Design Influence Behavior. Rockport Publishers.

[4] Haley, A., Richard Poulin, Jason Tselentis, Tony Seddon, Gerry Leonidas, Ina Saltz, Kathryn Henderson, Tyler Alterman. 2012. Typography Referenced A Comprehensive Visual Guide to the Language, History, and Practice of Typography. Beverly: Rockport Publisher.

[5] Hofstetter, Fred T. 2001. Multimedia Literacy. Third edition. New York: McGraw Hill International Edition.

[6] Ilene, Strivzer. 2013. Type Rules!: The Designer's Guide to Professional Typograph. John Wiley \& Sons Publisher.

[7] Rustan, Surianto. 2011. Huruf Font Tipografi. Jakarta : Gramedia. Pustaka Utama. 